\title{
Insulin resistance in patients with type 1 diabetes assessed by glucose clamp studies: systematic review and meta-analysis
}

\author{
Esther Donga ${ }^{1}$, Olaf M Dekkers ${ }^{1,2}$, Eleonora P M Corssmit ${ }^{1}$ and Johannes A Romijn ${ }^{3}$ \\ ${ }^{1}$ Department of Endocrinology and Metabolic Diseases C7, Leiden University Medical Center, PO Box 9600, 2300 RC \\ Leiden, The Netherlands, '2Department of Clinical Epidemiology, Leiden University Medical Center, Leiden, \\ The Netherlands and ${ }^{3}$ Department of Internal Medicine, Amsterdam Medical Center, University of Amsterdam, \\ Amsterdam, The Netherlands
}

Correspondence should be addressed to E Donga

Email e.donga@elisabeth.nl

\begin{abstract}
Objective: The aim of this study was to perform a systematic review and meta-analysis on insulin resistance in adult patients with type 1 diabetes mellitus compared to healthy controls, assessed by hyperinsulinemic euglycemic clamp studies. Design and methods: We conducted a systematic search of publications using PubMed, EMBASE, Web of Science and COCHRANE Library. Hyperinsulinemic euglycemic clamp studies comparing adult patients with type 1 diabetes mellitus to healthy controls were eligible. Primary outcome measures were pooled mean differences of insulin sensitivity of endogenous glucose production (EGP), of glucose uptake and of lipolysis. We estimated mean (standardized) differences and $95 \% \mathrm{Cls}$ using random effects meta-analysis.

Results: We included 38 publications in this meta-analysis. The weighed mean differences in EGP during hyperinsulinemia between patients and controls was $0.88(95 \% \mathrm{Cl}: 0.47,1.29)$ in the basal state and $0.52(95 \% \mathrm{Cl}: 0.09,0.95)$ in insulin stimulated conditions, indicating decreased hepatic insulin sensitivity in patients. Insulin sensitivity of glucose uptake was either reported as $M$ value (M), glucose infusion rate (GIR), glucose disposal rate (GDR) or metabolic clearance rate (MCR). Weighed mean differences were similar for $M-3.98(95 \% \mathrm{Cl}:-4.68,-3.29)$ and $\mathrm{GIR}-4.61(95 \% \mathrm{Cl}:-5.86,-3.53)$. Weighed mean difference for GDR was $-2.43(95 \% \mathrm{Cl}$ : $-3.03,-1.83)$ and $-3.29(95 \% \mathrm{Cl}:-5.37,-1.22)$ for $\mathrm{MCR}$, indicating decreased peripheral insulin sensitivity in patients. Insulin mediated inhibition of lipolysis was decreased in patients, reflected by increased non-esterified fatty acid levels.
\end{abstract}

Conclusions: Insulin resistance is a prominent feature of patients with type 1 diabetes mellitus and involves hepatic, peripheral and adipose tissues.

\section{Introduction}

Although type 1 diabetes mellitus is characterized by absolute insulin deficiency, type 1 diabetes is also associated with insulin resistance $(1,2)$. Insulin resistance is defined as a decreased biological response to a certain concentration of insulin. Impaired insulin action has been described in both poorly and adequately controlled patients with type 1 diabetes mellitus $(3,4)$, although the degree of insulin resistance varies substantially between patients $(2,5)$. In patients with type 1 diabetes (c) 2015 European Society of Endocrinology Printed in Great Britain mellitus, insulin resistance is an important risk factor for development of micro-and macrovascular complications $(5,6)$. Cardiovascular disease is still the leading cause of mortality in these patients (7). Therefore, it is important to understand the relation between insulin resistance and type 1 diabetes mellitus.

The hyperinsulinemic euglycemic clamp method, first described by DeFronzo et al. (8), is considered the reference standard for measurement of basal and insulin-stimulated

Published by Bioscientifica Ltd 
insulin sensitivity under a variety of circumstances. Using isotope tracers, tissue specific insulin sensitivity can be quantified (9). Briefly, insulin is infused intravenously at a constant rate in a subject after an overnight fast. Glucose is 'clamped' at a predetermined level (euglycemic clamp glucose $\sim 5 \mathrm{mmol} / \mathrm{l}$ or isoglycemic at basal glucose levels) by titrating a variable glucose infusion rate (GIR). As a consequence of hyperinsulinemia, glucose uptake in skeletal muscle and adipose tissue is increased, whereas lipolysis and EGP are suppressed. Under steady state conditions, the rate of glucose infusion equals the rate of glucose uptake by peripheral tissues. The degree of insulin resistance is inversely related to the amount of glucose necessary to maintain euglycemia. EGP can be calculated using isotope tracers of glucose and insulin resistance is reflected by increased EGP during a certain degree of hyperinsulinemia. Increased lipolysis, as a consequence of insulin resistance, results in increased levels of nonesterified fatty acids (NEFA). In summary, insulin resistance is characterized by decreased glucose uptake and increased EGP and NEFA levels.

Our aim was to perform a systematic review and metaanalysis on insulin resistance in adult patients with type 1 diabetes mellitus compared to healthy controls, assessed by hyperinsulinemic clamp studies.

\section{Methods}

\section{Data sources and searches}

In collaboration with a trained librarian, a search string was composed. The following databases were searched from their inception to December 1, 2013: PubMed, EMBASE, Web of Science, and COCHRANE Library. The search strategy consisted of the combination of three concepts:

i) Glucose clamp technique.

ii) Type 1 diabetes.

iii) Insulin resistance.

For these three items, relevant keyword variations were used, which included keyword variations in the controlled vocabularies of the various databases, and also free text word variations. The search strategy was optimized for all consulted databases, taking into account differences of controlled vocabularies as well as differences of database-specific technical variations. The reference lists of all potentially relevant articles were screened for additional publications. The search was restricted to the English language (see
Supplementary Table 1 , see section on supplementary data given at the end of this article for details of the literature search).

\section{Study selection}

Experimental studies using the hyperinsulinemic, iso- or euglycemic clamp technique comparing adult patients with type 1 diabetes mellitus and healthy controls were eligible.

We excluded studies in patients with renal and/or pancreatic transplantations, since immune suppressive drugs are known to induce insulin resistance. Studies performed in children and adolescents were beyond the scope of this review.

\section{Data extraction and risk of bias assessment}

Data extraction was performed independently by two investigators (ED and JAR) using a standard data-extraction sheet. In case of disagreement, consensus was reached after discussion with a third reviewer (OD).

Insulin sensitivity parameters were extracted as provided in the included studies. Information at the study level was extracted on i) patient characteristics (age, gender, mean duration of diabetes, BMI, insulin treatment, mean daily insulin use, HbA1c values), ii) clamp characteristics (including type of glucose clamp technique, use of stable isotopes), iii) type of outcome measure (EGP, glucose disposal rate (GDR, M), GIR, metabolic clearance rate (MCR) and levels of non-esterified free fatty acids (NEFA)).

In case authors compared one control group to two groups of patients with type 1 diabetes mellitus (i.e. poor vs well regulated diabetes), data of this control group were used twice in this meta-analysis. If necessary, values were recalculated to international system units, i.e. $\mathrm{mmol} / \mathrm{l}$ for glucose and pmol/l for insulin.

Assessment of risk of bias was based on study components that could potentially bias the association between insulin resistance and type 1 diabetes mellitus. The following components were considered: i) adequacy of the clamp protocol. The clamp protocol was considered adequate in case predetermined fixed insulin dose and predetermined steady state glucose levels were described and sampling of blood glucose levels was performed at brief intervals throughout the experiment. Furthermore, the duration of insulin infusion and the clamp should be described. ii) Adequacy of steady state in insulin-stimulated phase of glucose clamp study. Calculations of insulin 


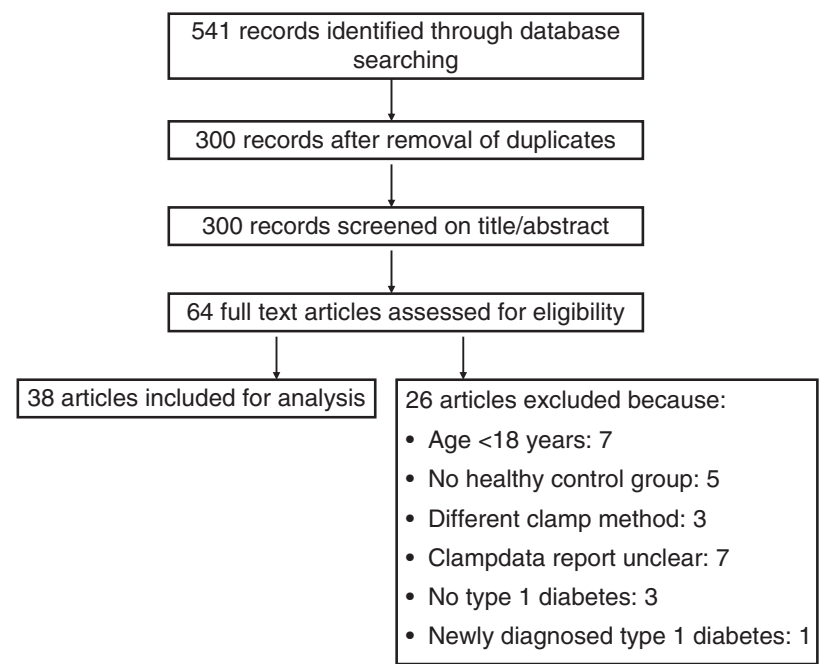

\section{Figure 1}

Summary of search results.

sensitivity parameters are based on the assumption that in steady state, glucose infusion equals glucose uptake. Studies were considered to have a low risk of bias in case duration of steady state, steady state insulin and glucose levels were reported and stable during steady state in both patients and controls. Studies that did not report steady state values for glucose and insulin were scored as unclear. iii) Inclusion of patients with poorly regulated diabetes, defined as an HbA1c level >9\%. Chronic hyperglycemia is known to increase insulin resistance (10) and, therefore, insulin resistance could be overestimated in these patients. iv) Presence of impaired glucose tolerance in healthy controls. Studies were considered to have a low risk of bias if healthy controls were reported to have a normal glucose tolerance, tested prior to the study.

\section{Data synthesis and analysis}

The primary outcome measures in this meta-analysis were pooled mean differences of EGP, peripheral glucose uptake and NEFA levels during hyperinsulinemic euglycemic clamp conditions in patients with type 1 diabetes compared to healthy controls. Parameters for peripheral glucose uptake could be reported as GDR, glucose metabolized ( $M$ value, $M$ ), GIR or MCR. Therefore, we used standardized mean outcome measures for peripheral glucose uptake to allow comparison between studies. Values for EGP, GDR, $M$ and GIR were reported in $\mathrm{mg} / \mathrm{kg}$ per min and recalculated if necessary when reported in other units. MCR was reported in $\mathrm{ml} / \mathrm{kg}$ per min and NEFA levels in $\mu \mathrm{mol} / \mathrm{l}$. We performed random effects metaanalysis using (standardized) mean differences and 95\% CIs. In case of $<5$ studies a fixed effect analysis was performed, as in such a circumstance the between study variance cannot be estimated reliably. We did not check formally for funnel plot asymmetry as all our included studies were of similar sample size. Statistical analyses were performed with STATA Statistical Software (Statacorp, College Station, TX, USA) version 12.1.

\section{Results}

\section{Search results}

The initial search included 300 publications after removal of duplicates and ultimately 64 articles were retrieved for detailed assessment (Fig. 1). Publications were excluded for the following reasons: no type 1 diabetes mellitus $(n=3)$, age of participants was below 18 years $(n=7)$, absence of a healthy control group ( $n=5)$, use of a clamp technique, not comparable to the iso-or euglycemic clamp method $(n=3)$, no quantitative outcome measures reported $(n=7)$ and one publication was excluded because participants had newly onset type 1 diabetes mellitus, in whom endogenous insulin production might be partly preserved. Finally, 38 publications were included in this meta-analysis, of which five publications $(11,12,13,14,15)$ consisted of two and one publication (16) of three studies.

\section{Study characteristics}

Study characteristics of included studies are presented in Table 1. In total, 38 publications were included, of which

Table 1 Study characteristics of the included publications. Range of means was reported of included studies.

\begin{tabular}{l}
\hline Characteristic \\
\hline Total participants \\
$\%$ men \\
Mean age (years) \\
Mean BMI (kg/m²) \\
Mean duration of diabetes \\
(years) \\
Mean daily insulin dose \\
(U/day) \\
Mean HbA1c (\%) \\
Clamp procedure \\
Insulin infusion rates clamp \\
(mU/m ${ }^{2}$ per min) \\
Mean glucose levels steady \\
state (mmol/l) \\
Mean insulin levels steady \\
state (pmol/l) \\
\hline
\end{tabular}

\begin{tabular}{cccc}
\cline { 1 - 1 } Patients & & Controls \\
\cline { 1 - 1 } 522 & & 698 \\
54 & & 55 \\
$22-50$ & & $23-64$ \\
$21.0-28.3$ & & $21.5-28.9$ \\
$1.2-38.9$ & & NA \\
$34-61$ & & NA \\
$5.6-14.2$ & & $4.8-6.6$ \\
$20-120$ & & $20-120$ \\
$4.0-9.6$ & & $4.0-5.5$ \\
$167-8972$ & & $160-7320$ \\
& & \\
\hline
\end{tabular}


Table 2 Potential sources of bias.

References Journal

\begin{tabular}{|c|c|c|}
\hline Isotopes & Steady state & Clamp protocol \\
\hline No & Yes & No \\
\hline Yes & Yes & Yes \\
\hline NR & NR & No \\
\hline NR & NR & NR \\
\hline Yes & Yes & Yes \\
\hline No & NR & Yes \\
\hline Yes & Yes & Yes \\
\hline No & Yes & Yes \\
\hline No & Yes & Yes \\
\hline Yes & NR & Yes \\
\hline No & Yes & Yes \\
\hline Yes & Yes & Yes \\
\hline No & Yes & Yes \\
\hline No & Yes & Yes \\
\hline Yes & Yes & Yes \\
\hline No & Yes & Yes \\
\hline No & Yes & No \\
\hline No & Yes & Yes \\
\hline No & Yes & Yes \\
\hline No & Yes & Yes \\
\hline No & Yes & Yes \\
\hline No & Yes & Yes \\
\hline No & Yes & Yes \\
\hline No & Yes & Yes \\
\hline No & Yes & Yes \\
\hline No & Yes & Yes \\
\hline Yes & Yes & Yes \\
\hline Yes & Yes & Yes \\
\hline No & No & Yes \\
\hline No & Yes & Yes \\
\hline No & NR & NR \\
\hline Yes & Yes & Yes \\
\hline No & Yes & Yes \\
\hline Yes & Yes & Yes \\
\hline Yes & Yes & Yes \\
\hline No & Yes & Yes \\
\hline Yes & Yes & Yes \\
\hline No & Yes & Yes \\
\hline
\end{tabular}

Controls without

(19)
Journal of Clinical Endocrinology and Metabolism

Journal of Clinical Endocrinology and Metabolism

Diabetes

ADA Conference

Diabetologia

Journal of Clinical Endocrinology and Metabolism

Diabetes/Metabolism Research

Diabetologia

Nephrology, Dialysis, Transplantation

Diabetologia

Journal of Clinical Endocrinology and Metabolism

Diabetologia

PLOS ONE

Journal of Internal Medicine

Hormone and Metabolic Research

Klinische Wochenschrift

Diabetologia

BMJ

Diabetes

Journal of Clinical Endocrinology and Metabolism

Circulation

Diabetologia

Diabetes Research and Clinical Practice

American Journal of Physiology

Diabetologia

Journal of Clinical Endocrinology and Metabolism

American Journal of Physiology

Diabetologia

Diabetic Medicine

Diabetes

Diabetic Medicine

Diabetes

Journal of Clinical Investigation

Journal of Clinical Endocrinology and Metabolism

Journal of Clinical Endocrinology and Metabolism

Journal of Clinical Endocrinology and Metabolism

Acta Endocrinologica and Reviews

Diabetes Care

NR, not reported

14 publications used stable isotope tracer infusions for assessment of tissue specific insulin sensitivity $(1,3,4,11$, $12,13,14,15,16,17,18,19,20,21,22,23,24,25,26,27$, $28,29,30,31,32,33,34,35,36,37,38,39,40,41,42,43$, $44,45)$. Mean age of included patients ranged from 22 to 50 years and from 23 to 64 years in healthy controls. BMI ranges in patients $\left(21-28 \mathrm{~kg} / \mathrm{m}^{2}\right.$ ) and controls (22-29 $\mathrm{kg} / \mathrm{m}^{2}$ ) were similar. Most clamp studies used the hyperinsulinemic euglycemic clamp method, and only two publications performed a hyperinsulinemic isoglycemic clamp. The insulin infusion rates and steady state insulin levels differed considerably between studies, and 


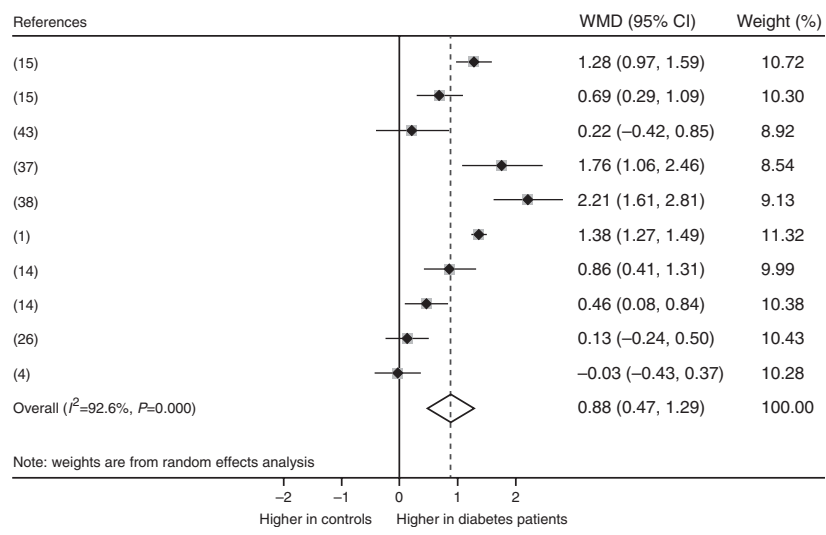

Figure 2

Basal endogenous glucose production.

ranged between 20 and $120 \mathrm{mU} / \mathrm{m}^{2}$ per min for insulin infusion rates and between 160 and $8972 \mathrm{pmol} / \mathrm{l}$ for steady state insulin levels. Both patients with short and long duration of disease were included and a large variation in diabetes regulation was present between studies.

\section{Risk of bias}

Risk of bias assessment is summarized in Table 2. Most publications (33 out of 38) reported an adequate clamp protocol. Steady state values and durations were reported in 32 publications. Twelve publications included patients with a mean HbA1c values $>9 \%$. Twenty-four publications did not report on impaired glucose tolerance in healthy controls. Overall, the risk of bias in the included publications was considered to be limited.

\section{Endogenous glucose production}

From studies using stable isotopes, ten studies reported data obtained during hyperinsulinemia on basal EGP and five studies on clamp EGP (Figures 2 and 3). In the basal state, mean EGP in diabetes patients varied from 2.0 to 4.5 $\mathrm{mg} / \mathrm{kg}$ per min vs 1.6 to $3.0 \mathrm{mg} / \mathrm{kg}$ per min in controls. The weighed mean difference in basal EGP between patients and controls was 0.88 (95\% CI: 0.47, 1.29), indicating less suppression of EGP in diabetic patients compared to controls. Under steady state hyperinsulinemic conditions, mean reported EGP values ranged from 0.0 to $1.2 \mathrm{mg} / \mathrm{kg}$ per min in diabetes patients and from 0.0 to $0.6 \mathrm{mg} / \mathrm{kg}$ per min in controls, with a weighed mean difference of 0.52 (95\% CI: 0.09, 0.95), compatible with less suppression of EGP under insulin-stimulated conditions. This means that
EGP during hyperinsulinemia was higher in patients compared to controls, indicating decreased hepatic insulin sensitivity in type 1 diabetes mellitus.

\section{Peripheral glucose uptake}

$M$ value, GIR, GDR and MCR during hyperinsulinemic clamp conditions are parameters of insulin-mediated glucose uptake (Fig. 4). Most clamp studies reported $M$ values $(n=14)$ or GIR $(n=15)$. Mean $M$ values ranged from 3.9 to $9.9 \mathrm{mg} / \mathrm{kg}$ per min for diabetic patients and from 7.0 to 14.0 for healthy controls. Mean GIR in patients varied between 2.4 and $8.9 \mathrm{mg} / \mathrm{kg}$ per min and in controls between 4.2 and $15.6 \mathrm{mg} / \mathrm{kg}$ per min. Weighed mean difference for $M$ was -3.98 (95\% CI: $-4.68,-3.29)$, in accordance with the weighed mean difference in GIR $(-4.61$ (95\% CI: $-5.86,-3.53)$ ). The weighed mean difference for GDR was -2.43 (95\% CI: $-3.03,-1.83)$ and weighed mean difference for MCR was -3.53 (95\% CI: $-4.06,-2.99)$. All values indicate decreased peripheral glucose uptake under insulin stimulated conditions, indicating decreased peripheral insulin sensitivity in patients with type 1 diabetes compared to healthy controls.

\section{Lipolysis and levels of NEFA}

Eleven studies reported data on basal NEFA levels and nine studies reported NEFA levels during clamp conditions (Figures 5 and 6). In the basal state, mean NEFA levels ranged from 473 to $1220 \mu \mathrm{mol} / \mathrm{l}$ in patients and 370 to 860 $\mu \mathrm{mol} / \mathrm{l}$ in healthy controls. NEFA levels during clamp conditions ranged from 20 to $380 \mu \mathrm{mol} / \mathrm{l}$ in patients and 10 to $390 \mu \mathrm{mol} / \mathrm{l}$ in controls. Weighed mean difference for basal NEFA levels between patients and controls was 134

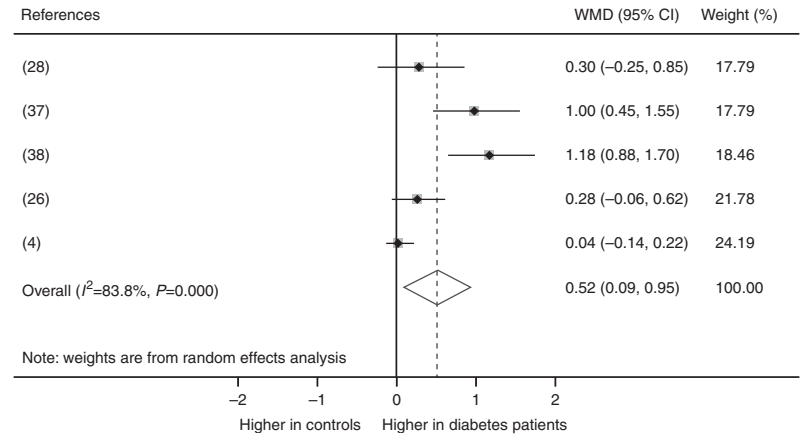

Figure 3

Clamp endogenous glucose production. 


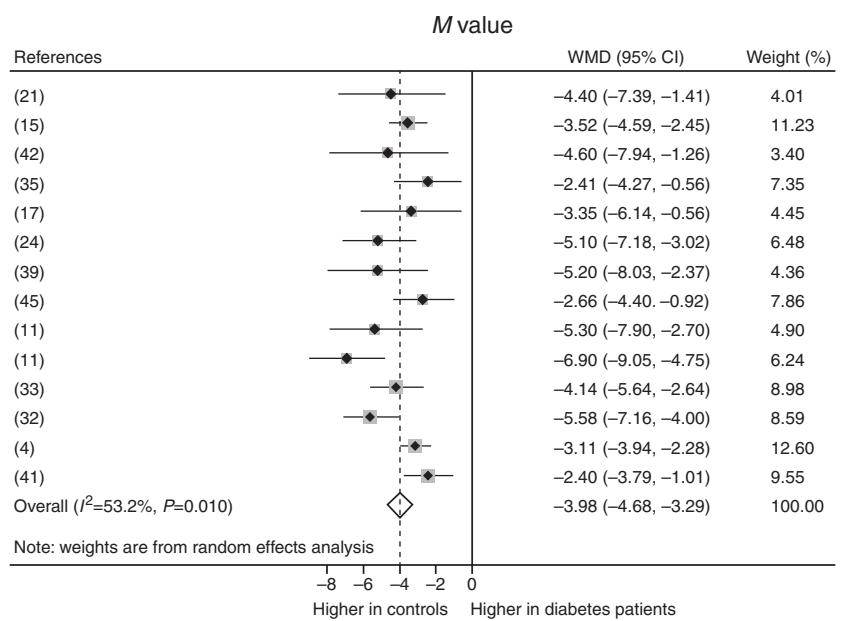

Figure 4

$M$ value.

(95\% CI: 7, 261) and for clamp NEFA levels 24 (95\% CI: 1, 47). This reflects decreased inhibition of lipolysis in patients with type 1 diabetes mellitus, and the values obtained during standardized hyperinsulinemic conditions indicate decreased insulin sensitivity of lipolysis.

\section{Discussion}

In this meta-analysis, we compared insulin resistance between patients with type 1 diabetes mellitus and healthy controls using data from hyperinsulinemic euglycemic clamp studies. The present meta-analysis shows that insulin resistance is a prominent feature of patients with type 1 diabetes mellitus which involves hepatic, peripheral and adipose tissues. This association is consistent and present in both poorly and well regulated patients.

Major strengths of this meta-analysis are the relatively large number of included publications and the large number of included participants, 522 patients and 698 controls. A limitation of this meta-analysis is the potential for confounding. For instance, in patients with type 1 diabetes recent hyperglycemia or hypoglycemia preceding the clamp study could have negatively influenced clamp outcome measures on insulin sensitivity $(46,47)$. Furthermore, the use of certain drugs is associated with decreased insulin sensitivity. For example, $\beta$ blockers and calcium channel antagonist are known to alter autonomic nervous system activity and decrease insulin sensitivity (48). In this meta-analysis, some publications excluded subjects who were using these drugs, whereas other publications did not report on the use of medication. Nonetheless, although we cannot completely exclude confounding, the findings from the included clamp studies are all very similar and consistently indicate decreased insulin sensitivity in multiple tissues in patients with type 1 diabetes mellitus. Clamp protocols differed substantially between included publications, although all studies refer to the same original study design by DeFronzo et al. (8). For instance, the insulin infusion rates and duration of the clamp procedures varied considerably, which resulted in a wide range of steady state insulin levels in the included clamp studies. Therefore, differences in insulin sensitivities found between clamp studies can be partly explained by different steady state levels of insulin. To allow comparison between studies, we only included publications directly comparing patients with type 1 diabetes mellitus with healthy controls.

In both clinical practice and clinical research, little attention is paid to insulin resistance as a common feature of type 1 diabetes mellitus. In contrast to studies in patients with type 2 diabetes mellitus, data on the effect of lifestyle factors on insulin sensitivity in type 1 diabetes mellitus are sparse (49). Although previous studies have assessed the relation between insulin resistance and development of cardiovascular complications, only a few studies are available on improving insulin resistance in type 1 diabetes mellitus. For example, Rosenfalck et al. (39) reported that a low fat diet during 3 months improved peripheral insulin sensitivity by $30 \%$ in patients with type 1 diabetes. A twelve week exercise program in adolescents with type 1 diabetes mellitus improved insulin sensitivity by $23 \%$, although this was not reflected in HbA1c levels (50). However, these studies looked at shortterm outcome measures and were not designed to

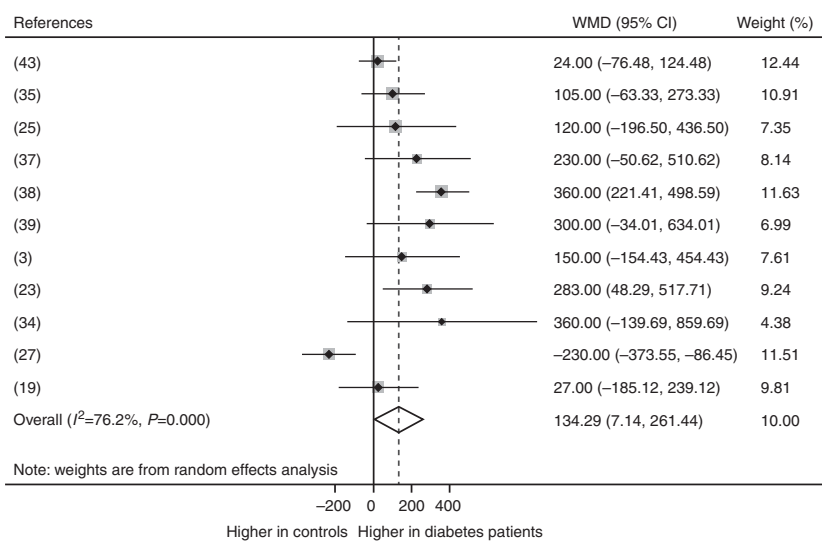

Figure 5

Basal non-esterified fatty acid (NEFA) levels. 


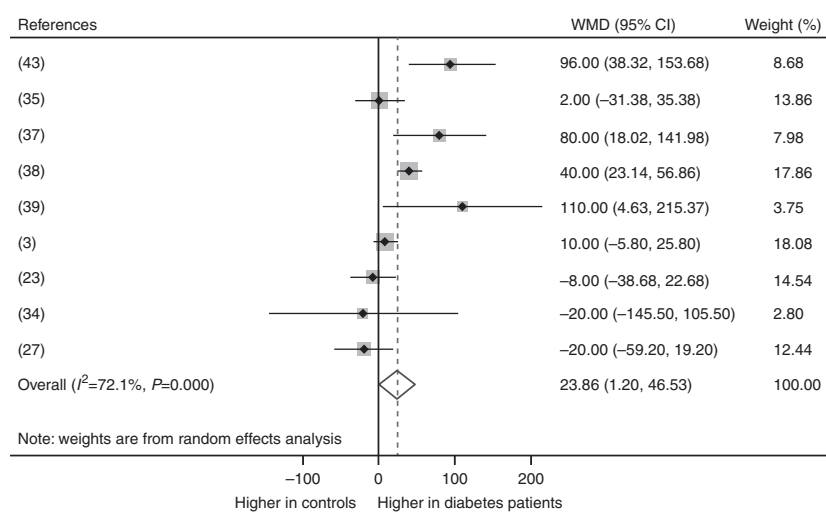

\section{Figure 6}

Clamp non-esterified fatty acid (NEFA) levels.

investigate the relation between improvement of insulin sensitivity in type 1 diabetes mellitus and prevalence of cardiovascular complications. Conversely, insulin resistance can be readily increased in patients with type 1 diabetes by only a single night of partial sleep deprivation (51). These intervention studies indicate that insulin resistance is not a fixed pathophysiological condition in patients with type 1 diabetes.

The pathophysiological basis of insulin resistance in multiple tissues in patients with type 1 diabetes is most likely to be complex. Different concepts have been introduced to explain the presence of insulin resistance in subgroups of patients with type 1 diabetes. The term 'double diabetes' was introduced for patients with type 1 diabetes, with a family history of type 2 diabetes who have a higher risk to develop components of type 2 diabetes at some age (52). This notion of 'double diabetes' should be differentiated from the accelerator concept, which proposes that autoimmune diabetes is triggered by factors like BMI and insulin resistance. However, neither of these two concepts fully explains the observations of the current meta-analysis, since the included studies were not merely obtained in subgroups of patients with type 1 diabetes.

Other factors that may be involved are the nonpulsatile pharmacokinetic profiles of exogenous insulin compared to normal endogenous insulin secretion and the posthepatic vs prehepatic route of insulin delivery in patients vs healthy subjects. Intermittent insulin exposure in patients with type 1 diabetes mellitus resulted in a $40 \%$ reduction in insulin delivery, compared to continuous insulin exposure (53). Chronic peripheral hyperinsulinemia could alter expression and activity of the insulin receptor and insulin signaling pathways in peripheral tissues (54). Hyperglycemia also contributes to the observed insulin resistance in patients with type 1 diabetes mellitus and intensive insulin treatment has shown to improve insulin sensitivity $(11,15)$.

Insulin resistance seems to reflect a general phenomenon in patients with type 1 diabetes mellitus. Nonetheless, it is possible that certain conditions in subgroups with type 1 diabetes including genetic factors and life style may exacerbate insulin resistance in patients with type 1 diabetes.

In conclusion, type 1 diabetes mellitus is characterized by both insulin deficiency and insulin resistance in multiple metabolic pathways. Therefore, studies are warranted to assess if interventions aimed at reducing insulin resistance provide clinical benefits in patients with type 1 diabetes mellitus.

Supplementary data

This is linked to the online version of the paper at http://dx.doi.org/10.1530/ EJE-14-0911.

\section{Declaration of interest}

The authors declare that there is no conflict of interest that could be perceived as prejudicing the impartiality of the research reported.

\section{Funding}

This research received no specific grant from any funding agency in the public, commercial or not-for-profit sectors.

Author contribution statement

E Donga and J A Romijn conceived this study, O M Dekkers and E Donga analyzed the data, and E Donga, O M Dekkers, Eleonora P M Corssmit and J A Romijn contributed to the collection of data. All authors critically reviewed various drafts of the manuscript, and all authors approved the final version. E Donga and J A Romijn are responsible for the integrity of the work as a whole.

\section{References}

1 DeFronzo RA, Simonson D \& Ferrannini E. Hepatic and peripheral insulin resistance: a common feature of type 2 (non-insulin-dependent) and type 1 (insulin-dependent) diabetes mellitus. Diabetologia 198223 313-319. (doi:10.1007/BF00253736)

2 Yki-Jarvinen H \& Koivisto VA. Natural course of insulin resistance in type I diabetes. New England Journal of Medicine 1986315 224-230. (doi:10.1056/NEJM198607243150404)

3 Kacerovsky M, Brehm A, Chmelik M, Schmid AI, Szendroedi J, Kacerovsky-Bielesz G, Nowotny P, Lettner A, Wolzt M, Jones JG et al. Impaired insulin stimulation of muscular ATP production in patients with type 1 diabetes. Journal of Internal Medicine 2011269 189-199. (doi:10.1111/j.1365-2796.2010.02298.x) 
4 Simonson DC, Tamborlane WV, Sherwin RS, Smith JD \& DeFronzo RA. Improved insulin sensitivity in patients with type I diabetes mellitus after CSII. Diabetes 198534 (Suppl 3) 80-86. (doi:10.2337/ diab.34.3.S80)

5 Orchard TJ, Olson JC, Erbey JR, Williams K, Forrest KY, Smithline KL, Ellis D \& Becker DJ. Insulin resistance-related factors, but not glycemia, predict coronary artery disease in type 1 diabetes: 10-year follow-up data from the Pittsburgh Epidemiology of Diabetes Complications Study. Diabetes Care 200326 1374-1379. (doi:10.2337/diacare.26.5. 1374)

6 Chaturvedi N, Sjoelie AK, Porta M, Aldington SJ, Fuller JH, Songini M, Kohner EM \& EURODIAB Prospective Complications Study. Markers of insulin resistance are strong risk factors for retinopathy incidence in type 1 diabetes. Diabetes Care, 2001 284-289. (doi:10.2337/ diacare.24.2.284)

7 Kilpatrick ES, Rigby AS \& Atkin SL. Insulin resistance, the metabolic syndrome, and complication risk in type 1 diabetes: "double diabetes" in the Diabetes Control and Complications Trial. Diabetes Care 200730 707-712. (doi:10.2337/dc06-1982)

8 DeFronzo RA, Tobin JD \& Andres R. Glucose clamp technique: a method for quantifying insulin secretion and resistance. American Journal of Physiology 1979237 E214-E223.

9 Rosenblatt J \& Wolfe RR. Calculation of substrate flux using stable isotopes. American Journal of Physiology 1988254 E526-E531.

10 Del Prato S, Matsuda M, Simonson DC, Groop LC, Sheehan P, Leonetti F, Bonadonna RC \& DeFronzo RA. Studies on the mass action effect of glucose in NIDDM and IDDM: evidence for glucose resistance. Diabetologia 199740 687-697. (doi:10.1007/s001250050735)

11 Fasching P, Ratheiser K, Damjancic P, Schneider B, Nowotny P, Vierhapper $\mathrm{H} \&$ Waldhausl W. Both acute and chronic nearnormoglycaemia are required to improve insulin resistance in type 1 (insulin-dependent) diabetes mellitus. Diabetologia 199336 346-351. (doi:10.1007/BF00400239)

12 Maahs DM, Hokanson JE, Wang H, Kinney GL, Snell-Bergeon JK, East A, Bergman BC, Schauer IE, Rewers M \& Eckel RH. Lipoprotein subfraction cholesterol distribution is proatherogenic in women with type 1 diabetes and insulin resistance. Diabetes 201059 1771-1779. (doi:10.2337/db09-1626)

13 Pereira RI, Snell-Bergeon JK, Erickson C, Schauer IE, Bergman BC, Rewers M \& Maahs DM. Adiponectin dysregulation and insulin resistance in type 1 diabetes. Journal of Clinical Endocrinology and Metabolism 201297 E642-E647. (doi:10.1210/jc.2011-2542)

14 Yki-Jarvinen H, DeFronzo RA \& Koivisto VA. Normalization of insulin sensitivity in type I diabetic subjects by physical training during insulin pump therapy. Diabetes Care 19847 520-527. (doi:10.2337/ diacare.7.6.520)

15 Yki-Jarvinen H \& Koivisto VA. Continuous subcutaneous insulin infusion therapy decreases insulin resistance in type 1 diabetes. Journal of Clinical Endocrinology and Metabolism 198458 659-666. (doi:10.1210/jcem-58-4-659)

16 Nijs HG, Radder JK, Frolich M \& Krans HM. The course and determinants of insulin action in type 1 (insulin-dependent) diabetes mellitus. Diabetologia 198932 20-27. (doi:10.1007/BF00265399)

17 Baron AD, Laakso M, Brechtel G \& Edelman SV. Mechanism of insulin resistance in insulin-dependent diabetes-mellitus - a major role for reduced skeletal-muscle blood-flow. Journal of Clinical Endocrinology and Metabolism 199173 637-643. (doi:10.1210/jcem-73-3-637)

18 Bergman BC, Howard D, Schauer IE, Maahs DM, Snell-Bergeon JK, Eckel RH, Perreault L \& Rewers M. Features of hepatic and skeletal muscle insulin resistance unique to type 1 diabetes. Journal of Clinical Endocrinology and Metabolism 201297 1663-1672. (doi:10.1210/jc. 2011-3172)

19 Bravard A, Lefai E, Meugnier E, Pesenti S, Disse E, Vouillarmet J, Peretti N, Rabasa-Lhoret R, Laville M, Vidal H et al. FTO is increased in muscle during type 2 diabetes, and its overexpression in myotubes alters insulin signaling, enhances lipogenesis and ROS production, and induces mitochondrial dysfunction. Diabetes $201160258-268$. (doi:10.2337/db10-0281)

20 Brown TL, Sippl RM \& Snell-Bergeon JK. 2012 Healthy pre-monopausal women with type 1 diabetes have increased peripheral insulin resistance compared to non diabetic women. Diabetes Conference: 72nd Scientific Sessions of the American Diabetes Association Philadelphia: June 2012.

21 Del Prato S, Nosadini R, Tiengo A, Tessari P, Avogaro A, Trevisan R, Valerio A, Muggeo M, Cobelli C \& Toffolo G. Insulin-mediated glucose disposal in type I diabetes: evidence for insulin resistance. Journal of Clinical Endocrinology and Metabolism 198357 904-910. (doi:10.1210/ jcem-57-5-904)

22 Donga E, van DM, Hoogma RP, Corssmit EP \& Romijn JA. Insulin resistance in multiple tissues in patients with type 1 diabetes mellitus on long-term continuous subcutaneous insulin infusion therapy. Diabetes/Metabolism Research and Reviews 201329 33-38. (doi:10.1002/ dmrr.2343)

23 Ebeling P, Essen-Gustavsson B, Tuominen JA \& Koivisto VA. Intramuscular triglyceride content is increased in IDDM. Diabetologia 1998 41 111-115. (doi:10.1007/s001250050875)

24 Ekstrand AV, Groop PH \& Gronhagen-Riska C. Insulin resistance precedes microalbuminuria in patients with insulin-dependent diabetes mellitus. Nephrology, Dialysis, Transplantation 199813 3079-3083. (doi:10.1093/ndt/13.12.3079)

25 Greenfield JR, Samaras K \& Chisholm DJ. Insulin resistance, intraabdominal fat, cardiovascular risk factors, and androgens in healthy young women with type 1 diabetes mellitus. Journal of Clinical Endocrinology and Metabolism 200287 1036-1040. (doi:10.1210/jcem. 87.3.8324)

26 Hother-Nielsen O, Schmitz O, Bak J \& Beck-Nielsen H. Enhanced hepatic insulin sensitivity, but peripheral insulin resistance in patients with type 1 (insulin-dependent) diabetes. Diabetologia 198730 834-840.

27 Hsu WC, Okeke E, Cheung S, Keenan H, Tsui T, Cheng K \& King GL. A cross-sectional characterization of insulin resistance by phenotype and insulin clamp in East Asian Americans with type 1 and type 2 diabetes. PLOS ONE 20116 e28311. (doi:10.1371/journal.pone.0028311)

28 Keller U, Muller R \& Berger W. Sulfonylurea therapy fails to diminish insulin resistance in type I-diabetic subjects. Hormone and Metabolic Research 198618 599-603. (doi:10.1055/s-2007-1012384)

29 Kerner W, Navascues I, von ST, Fussganger R, Arias P \& Pfeiffer EF. Characterization of insulin resistance in type I diabetes. Klinische Wochenschrift 198563 545-553. (doi:10.1007/BF01733199)

30 Kruszynska YT, Petranyi G, Home PD, Taylor R \& Alberti KG. Muscle enzyme activity and insulin sensitivity in type 1 (insulin-dependent) diabetes mellitus. Diabetologia 198629 699-705. (doi:10.1007/ BF00870279)

31 Lager I, Lonnroth P, von SH \& Smith U. Reversal of insulin resistance in type I diabetes after treatment with continuous subcutaneous insulin infusion. BMJ 1983287 1661-1664. (doi:10.1136/bmj.287.6406.1661)

32 Makimattila S, Virkamaki A, Groop PH, Cockcroft J, Utriainen T, Fagerudd J \& Yki-Jarvinen H. Chronic hyperglycemia impairs endothelial function and insulin sensitivity via different mechanisms in insulin-dependent diabetes mellitus. Circulation 1996a 94 1276-1282. (doi:10.1161/01.CIR.94.6.1276)

33 Makimattila S, Virkamaki A, Malmstrom R, Utriainen T \& YkiJarvinen $\mathrm{H}$. Insulin resistance in type I diabetes mellitus: a major role for reduced glucose extraction. Journal of Clinical Endocrinology and Metabolism 1996b 81 707-712.

34 Nijs HG, Radder JK, Poorthuis BJ \& Krans HM. Glucose disposal and intermediary metabolism during one year of continuous subcutaneous insulin infusion (CSII). Diabetes Research and Clinical Practice 199112 1-9. (doi:10.1016/0168-8227(91)90124-V)

35 Nuutila P, Knuuti J, Ruotsalainen U, Koivisto VA, Eronen E, Teras M, Bergman J, Haaparanta M, Voipio-Pulkki LM \& Viikari J. Insulin 
resistance is localized to skeletal but not heart muscle in type 1 diabetes. American Journal of Physiology 1993264 E756-E762.

36 Pernet A, Trimble ER, Kuntschen F, Damoiseaux P, Assal JP, Hahn C \& Renold AE. Insulin resistance in type 1 (insulin-dependent) diabetes: dependence on plasma insulin concentration. Diabetologia 198426 255-260. (doi:10.1007/BF00283646)

37 Perseghin G, Lattuada G, Danna M, Sereni LP, Maffi P, De CF, Battezzati A, Secchi A, Del MA \& Luzi L. Insulin resistance, intramyocellular lipid content, and plasma adiponectin in patients with type 1 diabetes. American Journal of Physiology. Endocrinology and Metabolism 2003285 E1174-E1181. (doi:10.1152/ajpendo.00279.2003)

38 Perseghin G, Lattuada G, De CF, Esposito A, Costantino F, Canu T, Scifo P, De TF, Maffi P, Secchi A et al. Reduced intrahepatic fat content is associated with increased whole-body lipid oxidation in patients with type 1 diabetes. Diabetologia 200548 2615-2621. (doi:10.1007/s00125005-0014-5)

39 Rosenfalck AM, Almdal T, Viggers L, Madsbad S \& Hilsted J. A low-fat diet improves peripheral insulin sensitivity in patients with Type 1 diabetes. Diabetic Medicine 200623 384-392. (doi:10.1111/j.1464-5491. 2005.01810.x)

40 Schauer IE, Snell-Bergeon JK, Bergman BC, Maahs DM, Kretowski A, Eckel RH \& Rewers M. Insulin resistance, defective insulin-mediated fatty acid suppression, and coronary artery calcification in subjects with and without type 1 diabetes: the CACTI study. Diabetes 201160 306-314. (doi:10.2337/db10-0328)

41 Shay CM, Secrest AM, Miller RG, Strotmeyer ES, Goodpaster BH, Kelsey SF \& Orchard TJ. Femoral-gluteal adiposity is not associated with insulin sensitivity in type 1 diabetes. Diabetic Medicine 201229 1407-1411. (doi:10.1111/j.1464-5491.2012.03728.x)

42 Tessari P, Nosadini R, Trevisan R, De Kreutzenberg SV, Inchiostro S, Duner E, Biolo G, Marescotti MC, Tiengo A \& Crepaldi G. Defective suppression by insulin of leucine-carbon appearance and oxidation in type 1, insulin-dependent diabetes mellitus. Evidence for insulin resistance involving glucose and amino acid metabolism. Journal of Clinical Investigation 198677 1797-1804. (doi:10.1172/JCI112504)

43 Trevisan R, Nosadini R, Avogaro A, Lippe G, Duner E, Fioretto P, Deana R, Tessari P, Tiengo A \& Velussi M. Type I diabetes is characterized by insulin resistance not only with regard to glucose, but also to lipid and amino acid metabolism. Journal of Clinical Endocrinology and Metabolism 198662 1155-1162. (doi:10.1210/jcem-62-6-1155)

44 Yki-Jarvinen H, Taskinen MR, Kiviluoto T, Hilden H, Helve E, Koivisto VA \& Nikkila EA. Site of insulin resistance in type 1 diabetes: insulin-mediated glucose disposal in vivo in relation to insulin binding and action in adipocytes in vitro. Journal of Clinical Endocrinology and Metabolism 1984b 59 1183-1192. (doi:10.1210/ jcem-59-6-1183)

45 Yki-Jarvinen H, Helve E \& Koivisto VA. Relationship between oral glucose tolerance and insulin sensitivity in healthy man and type 1 diabetic patients. Acta Endocrinologica 1986112 355-360.

46 Sandoval DA, Guy DL, Richardson MA, Ertl AC \& Davis SN. Acute, same-day effects of antecedent exercise on counterregulatory responses to subsequent hypoglycemia in type 1 diabetes mellitus. American Journal of Physiology. Endocrinology and Metabolism 2006290 E1331-E1338. (doi:10.1152/ajpendo.00283.2005)

47 Yki-Jarvinen H, Helve E \& Koivisto VA. Hyperglycemia decreases glucose uptake in type I diabetes. Diabetes 198736 892-896. (doi:10.2337/diab.36.8.892)

48 Jacob S, Rett K, Wicklmayr M, Agrawal B, Augustin HJ \& Dietze GJ. Differential effect of chronic treatment with two beta-blocking agents on insulin sensitivity: the carvedilol-metoprolol study. Journal of Hypertension 199614 489-494. (doi:10.1097/00004872199604000-00012)

49 Chimen M, Kennedy A, Nirantharakumar K, Pang TT, Andrews R \& Narendran P. What are the health benefits of physical activity in type 1 diabetes mellitus? A literature review Diabetologia 201255 542-551. (doi:10.1007/s00125-011-2403-2)

50 Landt KW, Campaigne BN, James FW \& Sperling MA. Effects of exercise training on insulin sensitivity in adolescents with type I diabetes. Diabetes Care 19858 461-465. (doi:10.2337/diacare.8.5.461)

51 Donga E, van DM, van Dijk JG, Biermasz NR, Lammers GJ, van KK, Hoogma RP, Corssmit EP \& Romijn JA. Partial sleep restriction decreases insulin sensitivity in type 1 diabetes. Diabetes Care 201033 1573-1577. (doi:10.2337/dc09-2317)

52 Teupe B \& Bergis K. Epidemiological evidence for "double diabetes". Lancet 1991337 361-362. (doi:10.1016/0140-6736(91)90988-2)

53 Bratusch-Marrain PR, Komjati M \& Waldhäusl WK. Efficacy of pulsatile versus continuous insulin administration on hepatic glucose production and glucose utilization in type I diabetic humans. Diabetes 198635 922-926. (doi:10.2337/diab.35.8.922)

54 Catalano KJ, Maddux BA, Szary J, Youngren JF, Goldfine ID \& Schaufele F. Insulin resistance induced by hyperinsulinemia coincides with a persistent alteration at the insulin receptor tyrosine kinase domain. PLOS ONE 20149 e108693. (doi:10.1371/journal.pone. 0108693)

Received 23 October 2014

Revised version received 31 March 2015

Accepted 20 April 2015 